Article

\title{
Innovative Perspective of Marketing Engagement: Enhancing Users' Loyalty in Social Media through Blogging
}

\author{
Muhammad Sajjad ${ }^{1}$ and Umer Zaman ${ }^{2, *(1)}$ \\ 1 Vehari Campus, COMSATS University Islamabad, Islamabad 61100, Pakistan; geosajjad@cuivehari.edu.pk \\ 2 Endicott College of International Studies, Woosong University, Daejeon 300-718, Korea \\ * Correspondence: umerzaman@endicott.ac.kr
}

Received: 29 July 2020; Accepted: 20 September 2020; Published: 22 September 2020

check for updates

\begin{abstract}
The breakneck pace of digital technologies has created a dramatic shift in marketing campaigns to engage users through unique and innovative experiences. Focusing on the same grounds, this study relates the market engagement with users' loyalty (UL) for Facebook social media. Market engagement has been measured through four constructs of innovative engagement (IE), functional engagement (FE), emotional engagement (EE), and communal engagement (CE). Blogging has been included as a moderator in the relation between IE, FE, EE, CE, and UL. To measure these relationships, study proposed two models and developed five hypotheses. Data were collected through structured questionnaire aimed at referral groups i.e., habitual users of Facebook. A total of 309 responses were included in the analysis through purposive sampling. Model 1 was tested with simple regression and it was found that the overall model was statistically significant and explained 65 percent of variation in UL. It was concluded that for online users, loyalty is affected by IE, FE, and CE, while EE is of least concern for them. Model 2 was tested through hierarchical regression after the inclusion of a moderator of $\mathrm{BE}$ in model 1. It was concluded that blogging acted as a partial moderator in between the relationship of IE, FE, EE, CE, and UL as the proposed model 2 was found to be significant. However, only CE yielded significant relationship with UL while IE, FE, and EE yielded insignificant relationship with UL in the presence of a moderator. The study concedes new insights for those social platforms and marketing companies that are seeking innovative and unique ways to retain their online users for long time.
\end{abstract}

Keywords: technologies to support innovation; marketing engagement; functional engagement; innovative engagement; emotional engagement; communal engagement; blogging; users' loyalty; multiple regression; moderation; electronic products; E-commerce

\section{Introduction}

Social media platforms have revolutionized the engagement mindset of modern businesses that generate innovative content to create loyal customers and extend brand's outreach [1,2]. Users loyalty can be enhanced if these platforms successfully retain them with their novel tactics [3]. A social organization is known to be engaged in marketing when it deliberately made efforts to attract, persuade, empower, and retain its users [4,5]. This action of organization is beyond its core and economic boundaries but if successful, that organization may earn abnormal profits by raising the number of its users [6]. Social media connects the people worldwide by engaging people [7] with diverse backgrounds. Loyalty of these users seemed to be a cumbersome job for any social media platform. There are multiple techniques to allure the attraction of these users. One common way is to identify the major clusters of collective interest of the users and then serving these clusters turn by turn. Here, the big hurdle for social media 
managers is to truly identify the similar patterns from giga bytes of data and to identify the loyal users [8]. However, the advantage of social media handlers is that the activities of these users' can be easily tracked and then can be directed through push notifications. Access to such tracked data related to social media users' activities enabled marketers to identify those social media channels that are being frequently used and devise strategies to engage its customers through planned intervention [9].

The effectiveness of engaging users for loyalty depends on multiple factors. These factors are ability to respond to its users in a timely way, identification of their issues in a systematic manner, and resolving these problems rigorously. Leveraging the users by providing them with value added featured services and comprehensive feedback truly based on the real time data enhances the effectiveness of social media platforms [10]. The nature of competition for acquiring social media users is very competitive and unique as users of social media have larger social networks around the globe. This switch over option increased the influential power of the users and an erroneous step of any social media platform may lead it toward failure. Retaining the users with the help of marketing engagement techniques is entirely different from traditional marketing techniques. It cannot be termed as the "old wine in new bottle" but it is the thoughtful effort by the marketers that produced the volunteers who are not only the loyal users but persuade others to use these platforms. To be competitive, firms have to face sustainability, global, and technological challenges. For adaption of successful technological challenge, it is mandatory to have skillful workforce and to identify new opportunities [11]. This study argues that social media can be this potential and new opportunity.

Social media acts as a central hub to connect these volunteers instantly at no additional cost. When users are engaged in social media marketing strategies, they actively contribute and participate in the marketing campaigns that are beneficial for these platforms. Before the advent of social media, one popular method of communication was the word of mouth communication where loyal customers persuade others for purchasing or using their favorite product. Such word of mouth communication also enhances the social learning of the customers [12]. Beginning of social media changed the relationship of this word of mouth communication into electronic word of mouth communication [13] where such communication changed the relationship between users engagement and its loyalty level. By observing the web trafficking and analytics, this media was found to be correlated with consumers' preferences by influencing their mentality even in the most tragic period [14]. Apart from these marketing efforts, users' wallet shares and purchasing power are also considered to be very important in relation to retention and loyalty. The abundance of users' private information enables marketers to thoroughly dig out such information and specifically target those segments who have the affordability and sufficient disposable income for purchase. Such information also helps the organization to retain its loyal customers and get rid of undesired ones. This is the utmost crux of marketing engagement to gauge the loyalty of social media users. Prior studies related to consumers engagement are either exploratory $[9,15]$ or highlighted that mining the social media is still a challenging job that is intended to overcome by the underlying study [16].

This study specifically initiated to answer the question that what is the relationship of market engagement factors with users' loyalty in social media. Moreover, the commitment and loyalty of the users can deteriorate by the opinion of experts. On social media the opinions of experts are in the form of blogs and these blogs are very important for the users when they intend to purchase an online product from any E-commerce website. So, this study also attempted to answer the question by focusing on how the opinions from blogging alters the preferences and loyalty of social media users. The study has two-fold purposes, first to measure the loyalty level of social media users' through marketing engagement. Second, to measure the effect of blogging in the relationship between marketing engagement and loyalty. Very few studies have considered the relationship of marketing engagement to measure the relationship of social media users. The underlying study not only focused on this relationship but also intended to measure the role of blogging in the said relationship by contributing to the body of knowledge. The study has the following major objectives: (1) What is the relationship between Marketing engagement and users' loyalty? (2) to what extent the blogging alters 
the relationship between marketing engagement and loyalty of users? Achieving the above mentioned objectives have the importance in the sense that digital technologies have shrunk the whole world into a global village. Now the online users' have enhanced knowledge as the access to information is on their fingertips. Through this easy-to-access information, these users can compare and select their choices from local markets to international markets. Ultimately, firms are forced to devise new strategies to tackle such complex digital competition from local to global level. The study uniquely proposed a moderating variable of blogging to enhance the loyalty level of social media users that can be proved as a deliberate effort by the marketing firms to make them competitive at an international level.

\section{Literature Review}

Users' use of social media is gradually increasing with the advancement of technology and ease of access to these sites. Now, the users can access these sites with their tiny mobile through free or less costly internet bundles [17]. To be competitive, small- and medium-sized companies have to work in an efficient manner. Adaptation of such methodologies may be termed as transitional ones. These companies have to be competitive at a global level even serving at local level. To earn the loyalty, product delivery time, its price, and quality cannot be compromised. For all this, social media played a vital role as the use of social media is pervasive, so the social media handlers require continued use and commitment of their users to increase their business operations [18]. Open innovation synergies aid in improving performance, gaining competitive advantage and sustainability by building networks purposefully $[19,20]$. Companies are struggling hard to develop and foster entrepreneurial orientations to compete in complex and dynamic environments that depend on company's capacity toward innovation [21]. The dynamics and complexities of an open innovation system cannot be understood without considering the organizational culture [22]. The model of quadruple helix (HQ) that integrates industry, government, academia, and society, can further enhance the impact of open innovation initiatives far beyond the organizational boundaries [23].

Prior literature has focused on industry type, administration, and role of academia for open innovation; however, this study uniquely addressed the role of social media for open innovation dynamics where the users can be engaged with novel and innovative tactics of blogging. Social media is considered a new emerging market for the firms and for new evolving markets sustainability principles play a vital role in drawing attention and maintaining relations with customers or users [24]. To enhance the commitment and loyalty of its users, social media handlers devise plenty of marketing tactics so that these users spend more times on these sites. These tactics come under the heading of marketing engagement [25]. Hawkins and Vel [26] observed that rise of social media facilitated its users to build and share their opinions and to strengthen their social relationships. These relationships have certain implications for business owners and for marketers. By observing these associations, they can exploit the users attitudinal and behavioral loyalty toward using social media.

\subsection{Users' Loyalty}

Users' loyalty (UL) is the psychological bond of user or social media user with websites that are frequently visited. Although, social media users engage in plenty of activities including alternate searches, their evaluation, and comparison with their favorite brand. In fact, the loyalty can be measured through several ways. In simple word, loyalty is the continuous use of that particular product. In social media usage, the users' loyalty can be measured by its continuous surfing of that site $[25,27]$. The hard-core loyalty will not be just limited to surfing but associating it with other tasks as well. For example, users surf the social media to enhance and strengthen social relationships but at the same time, they also focus on other activities that are not related to building social relationships. These may be viewing the ads of interest, watching clips of interest, and last but not least making a purchase with the help of social media usage. This can be done by clicking the advertising links available on the social media site. The users' satisfaction level enhanced if the required online purchase meets its expectation which ultimately enhances his/her level of commitment. Commitment and loyalty 
are part and parcel of each other so if the commitment level is high, there is likelihood that the loyalty level is also very high [28].

\subsection{Innovative Engagement}

Innovative engagement (IE) is the condition when users of the social media seek new or unique ideas on these sites. For novice users, there is plenty of surprises in the form of new creations and designs while for experts, there are methods and procedures from where they can easily judge and compare the innovativeness of processes [29]. Innovation is found to have positive association with firm performance. In fact, innovation plays an intermediary role among the firms' functional deliverables and its overall performance. The outcome of this innovation is enhanced earnings for the business [30]. According to Sawhney, et al. [31], Internet or social media has developed a new type of innovation which is known as collaborative innovation. Here, the users seek the value-added products and services and can share these innovations with their peers or friends. The interesting point to be noted is that social media usage does not restrict its users only to local innovations but it gives them a chance to seek the innovative ideas, products, and services around the globe, hence IE leads toward the notion of global engagement [32]. The users' level of confidence enhances when the new and innovative ideas meet their expectations. According to Foroudi et al. [33], users' loyalty is directly associated with the innovative capability, experience, and reputation of that product so they are more engaged with it. From above, it can be concluded that IE and loyalty are associated with each other, hence it can be hypothesized that:

Hypothesis 1a (H1a). Innovative engagement (IE) positively and significantly affects the users' loyalty (UL) toward using social media.

\subsection{Functional Engagement}

Functional engagement (FE) is the users' active and real-time participation on the platform of the social media [34]. When users' actively surf and modify the contents of social media then this act of the user is known as interaction. Brooks et al. [35] concluded that the completion of assignment and enhancement in task behavior can be explained through FE for self-recruiting and self-monitoring. In recent years, this interactivity has extended to relational activity rather than just interface activity [36]. These interactivities are from humans to humans and from humans to machines. The purpose of these interactivities is to accelerate the communication to other users by using the platform of social media. Functional engagement is known as the key performance indicator for the effectiveness of any marketing endeavor. FE can be measured from the hashtags, their popularity, likes, sharing, trends, and from the feedback of the users. Tomar et al. [37] also confirmed the importance of FE in their study and concluded that FE benefits the social media sites in multiple ways including the improvement of users' loyalty. Hence this study hypothesizes relationship of FE with UL in the following way.

Hypothesis $\mathbf{1 b}$ (H1b). Functional engagement (FE) positively and significantly affects the users' loyalty (UL) toward using social media.

\subsection{Emotional Engagement}

Emotional engagement (EE) are the feelings of social media users. Users have mixed feelings when they regularly access the social media websites. These feelings may be the feeling of joy, thrill, pleasure, excitement, and eagerness. The negative feelings may be the boredom, hesitation, frustration, anger, or disappointment. Usually, these feelings, either positive or negative, are the results of the contents viewed on the social media sites [38]. In both cases, if the users feel that they are emotionally attached with the viewed contents, they tend to share or pass these contents to their social groups. Although these feelings are proportional to the social media contents. Gerbaudo, et al. [39] found the strong relationship in between users' engagement and emotions for the UK election campaign through Facebook. However, 
these emotions can vary from person to person and also rely on their ethnic background. In reality, when users are engaged emotionally with the web-based environment, they actively participated in domain of these sites. Such active participation resulted in more social collaborations and learning [40]. Sometimes, these emotions can also be associated with the advertisement of these social sites [41]. However, EE can be different from the flow of involvement and behavior of the users [42]. Whatever the reason of emotional attachment of the users with the contents of social media, this attachment enhances the loyalty of the users toward the social media. Hence it is hypothesized that

Hypothesis 1c (H1c). Emotional engagement (EE) positively and significantly affects the users' loyalty (UL) toward using social media.

\subsection{Communal Engagement}

Majority of the users are on the social websites to strengthen their communal engagement (CE) with others. According to Hull and Lewis [43], CE allows users for collaboration who are alike in terms of their liking and disliking. Social media perhaps is the best central point that brings closer users that are geographically distributed. With the help of these channels, users can share their experiences and enhance their interactions with each other. Such engagements and interactions give rise to a virtual community having similar interests and mind sets [44]. It is easy for markets to target these virtual community groups. Promotional as well as motivational campaigns and small bounties lead the marketers to increase the commitment of these socially and virtually connected communities [45]. According to $\mathrm{Li}$, et al. [46] this social engagement is now transforming into new shape which may be termed as identification view of engagement. In fact, this new form of CE alters the users' temporal engagement into permanent engagement hence, improves the loyalty level of users. From above, it can be hypothesized that:

Hypothesis 1d (H1d). Communal engagement (CE) positively and significantly affects the users' loyalty (UL) toward using social media.

Based on the above literature, following conceptual framework has been developed. This framework depicts the direct relationship between IE, FE, EE, and CE on UL. The relationship is given below through a schematic diagram.

\subsection{Blogging}

With the rise of social media, a new way of computer-mediated communication has evolved which is termed as "blogging" or "web logs" or "social media blogs" [47]. These blogs have brought new insights, rules, and ways of competition for business owners. Blogs on social media alters the way of competition and all of such alterations are the result of rapid growth in technology, increased power of virtual communities, and the less control of marketers through traditional marketing practices [48]. To enhance their control on business, E-commerce websites were developed and for the promotion of these websites professional bloggers were hired. Such way of blogging completely reshaped the nature of competition. This innovative and unique way of marketing on social media platforms with the help of professional blogging is the true picture of engagement marketing. Blogging on social media can be in any from entailing from simple text to pictures, audio, or video files. Hynnä and Kyrölä [49] found the positive impact of blogs on a feminist fat study. These blogs were uploaded on a regular basis and helped the users to build their opinion. When users frequently visit these augmented blogs [50], they developed a sense of attachment or engagement with them.

The life of blogs is very short so it is considered like news in the journalism where readers seek new articles every day [51]. In reality, blogging for social media is entirely different from traditional journalism. Blogging on these entities acts as channels where users usually have to pay no cost but they can get the opinions of experts around the globe. The users from these blogs are actually mitigating their risk for future online purchases [52]. Through frequent consultancy and continuous 
feedback, users develop their perceptions of credibility for these blogs. So, the users share their good experiences with their social groups which ultimately increases the ratings of these blogs. This positive perception also leads the social media users to develop a sense of arousing engagement with these blogs. Such engagements affect the innovative, functional, communal, and emotional side of the social media users, ultimately increasing their loyalty level toward blogging [53].

Hsu, et al. [54] developed a conceptual model that represented the relationship between blogging and loyalty in the presence of a moderating variable. Motivation and identification theories provide the theoretical base for e-word of mouth (e-WOM) or blogging which can enhance the loyalty of electronic word for those businesses who are struggling for greater share in this new domain [55]. Innovation engagement marketing techniques have been found to have a positive and significant effect on loyalty in the presence of blogging for e-commerce websites [56].

From all the above discussion in the literature, it is evident that blogging significantly alters the perception and loyalty of social media users, so it can be considered a strong moderator for market engagement and loyalty of social media users. So, a new research model is proposed after the inclusion of a moderator. It is assumed that this moderator, "blogging," alters the strength of the relationship of IE, FE, EE, CE, and UL.

\section{Materials and Methods}

\subsection{Participants}

To achieve the sustainable growth for respective companies, this study was initiated to measure the extent of users' loyalty who actively used the social media and frequently went through the blogs on these platforms. The study targeted those web users who use Facebook as a social media and had purchased at least one online product from any E-commerce website after consulting from an opinion leader or from a blogger. Furthermore, this purchase was specified only to electronic products or accessories of electronic products linked through Facebook. Household items, apparels, life style, groceries, automotive, sports, health, and fashion related items and their online purchase were excluded in this study. Identification of such active users on Facebook was a big challenge as there is no comprehensive database or availability of secondary data pertaining such information.

Based on the theoretical framework in Figure 1, the following equation is stated to measure the strength and association of variables

$$
U L_{i}=\beta_{0}+\beta_{1} I E_{i}+\beta_{2} F E_{i}+\beta_{3} E E_{i}+\beta_{4} C E_{i}+\mu_{i}
$$

where

$U L=$ Users $^{\prime}$ loyalty in social media

$I E=$ Innovative engagement

$F E=$ Functional engagement

$E E=$ Emotional engagement

$C E=$ Communal engagement

$\beta_{i}=$ Regression coefficient

$\mu_{i}=$ Error term 


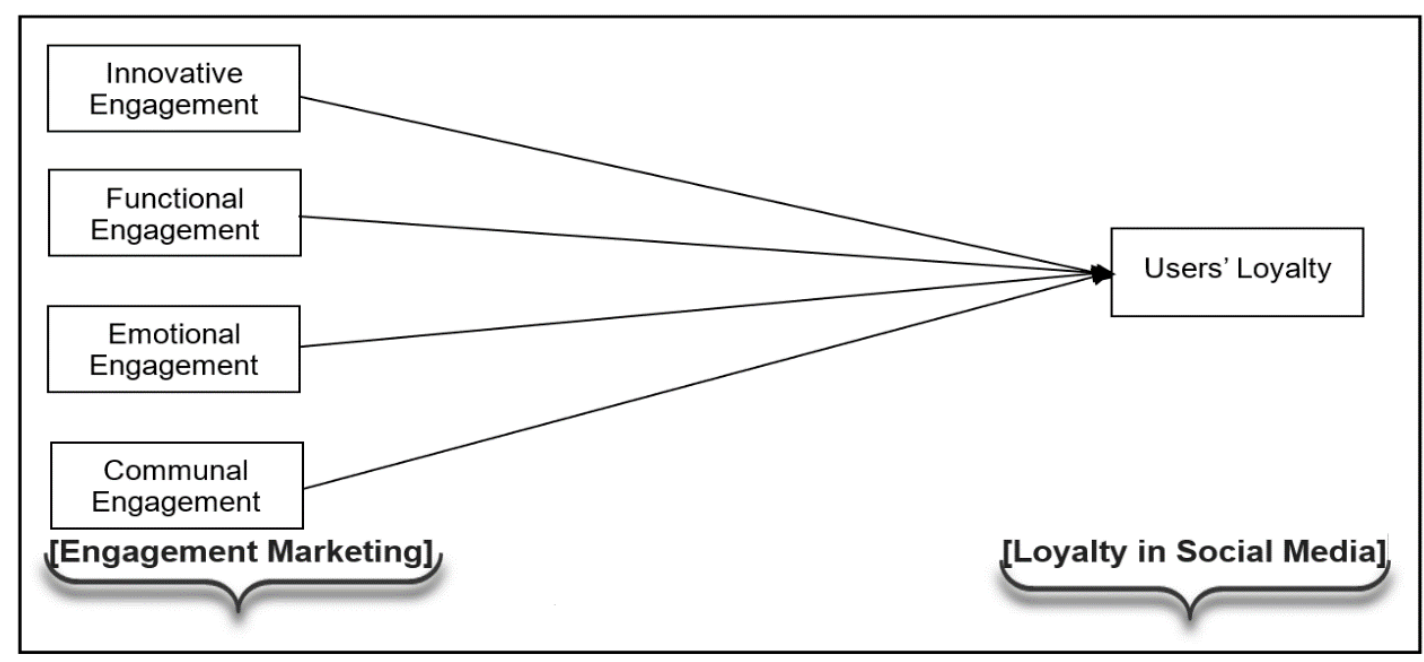

Figure 1. Proposed research model 1.

From the above equation, the main hypothesis of model 1 of the study can be hypothesized as:

Hypothesis 1 (H1). The dimensions of marketing engagement (IE, FE, EE, CE) positively and significantly affect the users' loyalty (UL) toward using social media.

From Figure 2, following equation has been proposed to measure the effect of moderator in between the relation of IE, FE, EE, and CE with UL

$$
\begin{gathered}
U L_{i}=\beta_{0}+\beta_{1} I E_{i}+\beta_{2} F E_{i}+\beta_{3} E E_{i}+\beta_{4} C E_{i}+\beta_{5}(I E \times B E)_{i}+\beta_{6}(F E \times B E)_{i}+\beta_{7}(E E \times B E)_{i} \\
+\beta_{8}(C E \times B E)_{i}+\mu_{i}
\end{gathered}
$$

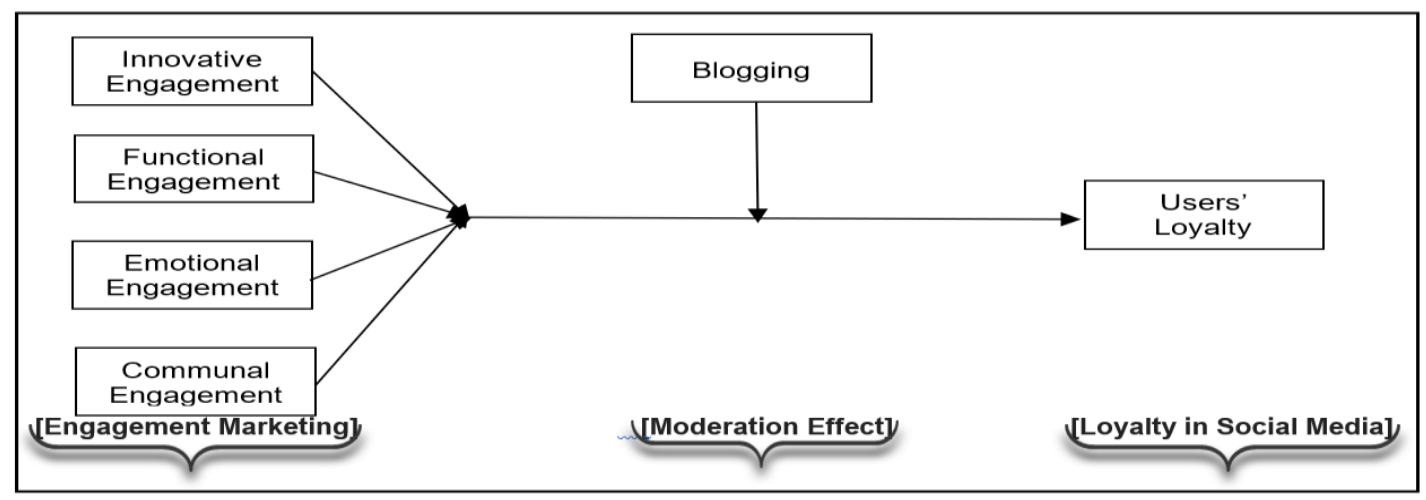

Figure 2. Proposed research model 2.

Following hypotheses were developed from model 2 after the inclusion of a moderator.

Hypothesis 2 (H2). Blogging on E-Commerce websites (BE) moderates the relationship of innovative engagement (IE) and users' loyalty (UL) toward using social media.

Hypothesis 3 (H3). Blogging on E-Commerce websites (BE) moderates the relationship of functional engagement (FE) and users' loyalty (UL) toward using social media.

Hypothesis 4 (H4). Blogging on E-Commerce websites (BE) moderates the relationship of emotional engagement (EE) and users' loyalty (UL) toward using social media. 
Hypothesis 5 (H5). Blogging on E-Commerce websites (BE) moderates the relationship of communal engagement (CE) and users' loyalty (UL) toward using social media.

\subsection{Procedure}

This study opted the primary data collection technique for collecting the responses from above mentioned social media users. Structured questionnaires were used to gather the information with three qualifying questions. These qualifying questions were: (1) Do you actively use the Facebook as a social media for communication? (2) Do you often seek help from blogs? (3) Have you recently purchased any electronic device from E-commerce website? These three questions were asked on dichotomous scale of yes or no. If the answers of all questions were yes, then the individual may further proceed to fill the remaining parts of the questionnaire. All the questionnaires were distributed by using purposive or non-probability sampling technique through acquaintances or through referral groups as this was the only option to identify and contact the targeted individuals. Schillewaert, et al. [57] applied non-probability sampling methods as a survey for world web users and concluded that complementary sampling is the best technique to collect the information from web users. By employing the same technique, this study collected the information from social media users to measure their loyalty level.

\subsection{Instrument}

Proceeding to the qualifying part of the scale, second part of the questionnaire was related to social media usage and blogging. The second part was subdivided into seven sections. In the first section, demographic information was collected while the remaining six sections consisted of questions related to main variables of the study. These variables are innovative engagement (IE), formal engagement (FE), emotional engagement (EE), communal engagement (CE), blogging (BE) and users' loyalty (UL) toward social media. Although the nature of marketing engagement is qualitative but all variables of the study have been adapted from previous and authenticated sources. Scales of FE, EE, CE, and UL were adapted from [34], IE was adopted from [58] while BE was adapted from [59]. All the variables consisted of four items except the BE with six items. All questions were asked on a 5-point Likert scale and responses were recorded from strongly disagree to strongly agree where the number 1 to 5 was assigned to each category and measured in a quantitative way.

Although the participants' selection was through purposive sampling and through referral groups but the participants had the liberty to answer the question voluntarily. Even the qualifying respondent had the right not to fill the questionnaire or quit without mentioning any reason. This was done to secure the respondent's rights and considering the ethical concerns of the underlying research. Anonymity and confidentiality of the respondents were also ensured. For all this, an introductory paragraph was included at the start of the questionnaire where the purpose of the research, researchers' information, and rights of the respondents were briefly mentioned. Apart from this, a member of research team was physically present with the respondent for clarity and to remove any ambiguity while filling out the questionnaires. A total of 309 filled questionnaires were collected and included in the study from a total of 500 personally distributed questionnaires. 191 questionnaires were either not returned or were not completed so leaving the response rate up to $61.8 \%$. English language was used in the questionnaire and no respondent was found to face any difficulty with the language as all of them were active users of social media and expert in surfing such platforms. Additionally, most of them seek opinions or share their expertise and experiences from blogging where English is the key language. Data from all responses were encoded and entered into SPSS for analysis and estimation.

\section{Data Analysis and Results}

The study employed the regression analysis to measure the significance of the proposed model. The proposed model of the study was checked in two stages. At first, for model 1, the simple regression analysis was run to measure the strength and power of the relationship between independent variables (IVs) and dependent variable (DV). In the second phase, the interaction term was introduced by 
multiplying the IVs with the moderator. Then the impact of moderating variable (MV) was checked in model 2. The analysis was done using the statistical package of social sciences (SPSS) version 23. Before estimation of regression, the reliability analysis was employed to measure the consistency and authenticity of the observed variables. The results of reliability and validity analysis are given below in Table 1.

Table 1. Reliability and validity analysis.

\begin{tabular}{ccccc}
\hline Variables & Cronbach's Alpha & Composite Reliability & AVE & No. of Items \\
\hline Innovative Engagement (IE) & 0.848 & 0.887 & 0.627 & 04 \\
Functional Engagement (FE) & 0.824 & 0.858 & 0.758 & 04 \\
Emotional Engagement (EE) & 0.895 & 0.713 & 0.592 & 04 \\
Communal Engagement (CE) & 0.786 & 0.855 & 0.764 & 04 \\
Blogging on E-Commerce (BE) & 0.864 & 0.882 & 0.658 & 06 \\
Users' Loyalty (UL) & 0.797 & 0.891 & 0.762 & 04 \\
\hline
\end{tabular}

The above Table 1 shows the inter item consistency of IVs, DV, and MV. A rule of thumb to measure the reliability of the items is that the calculated value of Cronbach's alpha for each variable should be greater than or equal to 0.7. Alpha is the distinct example of Kuder-Richardson coefficient and shows the inter item internal consistency [60]. In fact, alpha is the estimation of correlation from random samples and accepted widely for higher legitimacy for the scales used in the study. According to Santos [61], skewed data may affect the value alpha so the normality of data should be checked before measuring or estimating the values of Cronbach's alpha. The data were also checked for validity through factor analysis. All the values were found to be greater than 0.7 for all individual loadings. After this, the data were validated for convergent and discriminant validity. Convergent validity was assessed from the values of composite reliability. The scale is validated [62], if the values of composite reliability must be greater than 0.7. Here, in Table 1 , all CR values of the variables are above 0.8 except the value of EE which is also greater than 0.7. For discriminant validity, the value of average variance extracted (AVE) was observed. Discriminant validity was measured by comparing the square root of each construct by other constructs. The value of each construct must be greater than itself as compared to other constructs. All constructs have been found to be validated for discriminant validity as per practice of previous studies $[63,64]$. After observing that the criteria for all variables for reliability and validity were fulfilled, further analysis was done for descriptive analysis as well as for regression analysis.

Table 2 below shows the summary of descriptive statistics. A total of 309 respondents were included in the study where 251 were males and 58 were females. The valid percentage was 81.2 and 18.8 for males and females, respectively. The reason for less response rate from females was cultural constraints for sharing information and their least interest in purchasing online electronic products. Age was broadly divided into three categories: age less than 30 years, age in the range between 30 and 40 years, and age above 40 years. The valid percentage is 30, 50, and 20 respectively for each age group. This sample showed that majority of the respondents who purchased online electronic products were adults within age range from 30 to 40 years. Education was also categorized into three groups of undergraduate, master's, and graduate. The valid percentage for these three groups were 22, 71 , and 6, respectively. These statistics showed that a major portion of the respondents had a master's degree or 16 years of formal education and are adult males. 
Table 2. Descriptive statistics.

\begin{tabular}{ccccccccc}
\hline & \multicolumn{2}{c}{ Gender } & \multicolumn{2}{c}{ Age } & \multicolumn{2}{c}{ Education } \\
\hline & Males & Females & Less Than 30 & $31-40$ & Above 40 & Graduate & Masters & MPhil or PhD \\
\hline Percentage & 81 & 58 & 92 & 157 & 60 & 67 & 220 & 22 \\
\hline N & \multicolumn{2}{c}{309} & 30 & 51 & 19 & 22 & 71 & 7 \\
\hline
\end{tabular}

After the descriptive statistics and scale authentication, simple regression analysis was run to estimate the strength of relationship and level of significance between IVs and DV. Before running the regression analysis, the variables were checked for autocorrelation multicollinearity issues. No such issue was found in the data. The collinearity statistic was measured through variance inflation factor (VIF). The computed value of VIF for all variables was less than 2 whereas the threshold value for having collinearity issue was 3 or above. So, based on the calculated statistic of VIF, it was confirmed that data have no collinearity issue and perfectly fit to run regression analysis. The same was counterchecked with tolerance statistic and found no issue of multicollinearity in the data. All hypotheses of the study were tested at $95 \%$ confidence level with threshold value equal to or less than 0.05 . Model summary of the regression analysis is given below in Table 3.

Table 3. Regression analysis.

\begin{tabular}{cccccc}
\hline Model & $\mathbf{R}$ & R Square & Adjusted R Square & Std. Error of the Estimate & $p$ Value \\
\hline 1 & $0.650^{\text {a }}$ & 0.422 & 0.414 & 0.47132 & 0.000 \\
\hline \multicolumn{5}{c}{ a Dependent variable: UL, predictors: (constant), CE, EE, IE, FE. }
\end{tabular}

Table 3 (above) shows the summary of the regression analysis for IE, FE, EE, and CE (IVs) with UL (DV). Regression is a powerful technique of the statistical process, which the strength of the observed variables. These are the results before the inclusion of moderator or interaction terms. The results showed the strong and positive association between IE, FE, EE, CE, and UL. The value of R described that how close the fitted regression line is to the actual data. Its value ranges from 0 to 100 where 0 means no variability or model explanation while 100 means the model is fully explained by the predictors. Here the value of $R$ is 0.65 and the value of adjusted $R$ square is 0.414 which showed that the 41 percent of variation in the DV is explained by IVs. The probability value or $p$ value of the model is 0.000 which is a proof for the significance of the model as a whole. From above, it can be concluded that overall marketing engagement can be significantly associated with users' loyalty toward social media use. Individual predictors estimation was measured from coefficients, as shown in Table 4 below.

Table 4. Coefficients.

\begin{tabular}{|c|c|c|c|c|c|c|}
\hline \multirow{2}{*}{\multicolumn{2}{|c|}{ Model }} & \multicolumn{2}{|c|}{ Unstandardized Coefficients } & \multirow{2}{*}{$\begin{array}{c}\text { Standardized Coefficients } \\
\text { Beta }\end{array}$} & \multirow{2}{*}{$t$} & \multirow{2}{*}{$p$ Value } \\
\hline & & B & Std. Error & & & \\
\hline \multirow{5}{*}{1} & (Constant) & 0.548 & 0.260 & & 2.107 & 0.036 \\
\hline & IE & 0.271 & 0.046 & 0.291 & 5.880 & 0.000 \\
\hline & $\mathrm{FE}$ & 0.420 & 0.058 & 0.365 & 7.224 & 0.000 \\
\hline & $\mathrm{EE}$ & -0.062 & 0.055 & -0.051 & -1.130 & 0.260 \\
\hline & $\mathrm{CE}$ & 0.144 & 0.045 & 0.157 & 3.199 & 0.002 \\
\hline
\end{tabular}

Dependent variable: UL, predictors: (constant), CE, EE, IE, FE.

Table 4 statistically measures the individual effect of each variable on the dependent variable. From beta coefficients, the degree of change in dependent variable (UL) is measured by the IVs (IE, FE, EE, and CE) with 1-unit change in the predictors. Here in Table 4, all the beta values in standardized 
coefficients are positive except EE which shows that 1-unit change in EE adversely affects the UL up to 0.051 units. $t$ and sig. values show the statistically significant relationship between predictors and DV. The $t$ and $p$ values of IE, FE, and CE are 5.880, 7.224, 3.199, and 0.000 respectively which shows that IE, FE, and CE positively and significantly affect the UL. Based on these values, the study hypotheses No.1, 2, and 4 are accepted and it can be said that innovative, functional and communal engagement are important for users' loyalty toward using social media. From $t$ and $p$ value of EE, which is 1.13 and 0.260 , the null hypothesis No. 3 is rejected and it is concluded that emotional engagement cannot be associated with users' loyalty for using social media. Table 5 below gives the results of moderated regression.

Table 5. Moderated regression analysis.

\begin{tabular}{cccccc}
\hline Model & R & R Square & Adjusted R Square & Std. Error of the Estimate & $p$ Value \\
\hline 1 & $0.664^{\text {a }}$ & 0.440 & 0.431 & 0.46454 & 0.000 \\
2 & 0.676 & 0.457 & 0.441 & 0.46056 & 0.000 \\
\hline
\end{tabular}

${ }^{a}$ Dependent variable: UL, predictors: (constant), CE, EE, IE, FE, BE, predictors with interaction: (Constant), CE, EE, IE, FE, BE, IEBE, FEBE, EEBE, CEBE.

Moderation measures the strength of relationship between IVs and DV. Table 5 shows the summary of two models. Model 1 explains the relationship of variables without the interaction terms. On the other side, model 2 explains the relationship of variables in the presence of interaction terms or moderating variable. From the $p$ values in Table 5, for model 1 and 2, which are 0.000, it is evident that overall model is significant even after the inclusion of moderating variable or interaction terms. The value of $R$ for model 1 is 0.664 and for model 2 is 0.676 , a slight increase in the value of $R$. From this slight increase, it can be concluded that moderators positively affect and enhance the relationship among predictors and dependent variable. The results are also supported with the value of adjusted $R$ square where the explained variation has been increased from 43 percent to 44 percent. The results are sufficient enough to conclude that blogging on E-commerce websites strengths the relationship of marketing engagement and users' loyalty for using social media.

Table 6 below shows the individual relationship of each variable with dependent variable before and after the inclusion of interaction terms measured through hierarchical regression test. Standardized and unstandardized beta coefficients in Table 6 did not show any significant differences in the values of computed variables which is good sign for data normality [65] where standardized betas are the normalized units while the unstandardized betas are real-life scales. The standard error measures the level of dispersion of sample means from population means [66]. Here the low values of standard error in Table 6 confirmed that the data are not widely dispersed. For model 1 , the $t$ and $p$ values showed the positive and significant relationship of IE, FE, CE, and BE with UL. These values of $t$ and $p$ in model 1 are 5.616, 0.000 for IE, 6.588, 0.000 for FE, 2.295, 0.022 for CE and 3.153, 0.002 respectively. The values of $t$ and $p$ for EE are -1.254 and 0.211 , which show insignificant and negative relationship of EE with UL. These results further enhanced and supported the hypotheses No. 1, 2, and 4 of this study and rejected the hypothesis No. 3 . Model 2 is the result of interaction terms or exhibits the relationship between IVs and DV in the presence of a moderator. The $t$ and $p$ values of FEBE, EEBE, IEBE, and CEBE are 0.40 and $0.968,-1.218$ and $0.224,-0.680$ and $0.497,2.545$ and 0.011 , respectively. Comparing model 1 and 2, all the above mentioned values showed that the significance level of IE and FE changed after the inclusion of a moderator. This change can be observed from the $t$ and $p$ values of IEBE and FEBE in Table 6. Whereas, the significance level of EE and CE has not been changed after the inclusion of a moderator. EE remained insignificant while CE still had a significant relationship after the inclusion of moderator. The insignificant and significant values can be observed from $t$ and $p$ values of EEBE and CEBE in Table 5. In spite of the insignificance of IEBE, FEBE, and EEBE, the overall model 2 is significant after the inclusion of a moderator. This conclusion has been drawn from Table 5 where the $p$ value is 0.000 for overall model 2 . The explanatory power of the model 2 
has also been enhanced from 0.664 to 0.676 as seen in Table 5. Based on the computed values, it can be concluded that BE successfully moderates the relationship of CE and UL whereas the relationship between IE, FE, and EE remained insignificant after the inclusion of the moderator BE. From above, hypotheses No. 5-7 of the study are not supported where the level of significance changed after the inclusion of a moderator. The significance level CE remained same after introducing the interaction terms so, the study failed to reject the hypotheses No. 8. Based on the results, it can be safely said that blogging on E-commerce websites successfully moderates and strengthens the relationship and loyalty of social media users only for $\mathrm{CE}$ while the significance levels of innovative, functional, and emotional engagement are not affected with the inclusion of a moderator. CE has a significant relationship with BE because blogging acts as a suggestive part, while from the innovative, functional, and emotional point of view social media users still seek other characteristics in online purchasing. So, this study also offers new horizons for further research to identifying the influencing factors for IE, FE, and EE. From above, it is concluded that by considering the social media as a community of collaboration, the communal engagement of user is affected with the intrusion of blogging while for innovative, functional, and emotional engagements, blogging proved to be ineffective.

Table 6. Coefficients of regression and moderation.

\begin{tabular}{|c|c|c|c|c|c|c|}
\hline & & \multicolumn{2}{|c|}{ Unstandardized Coefficients } & \multirow{2}{*}{$\begin{array}{c}\text { Standardized Coefficients } \\
\text { Beta }\end{array}$} & \multirow{2}{*}{$t$} & \multirow{2}{*}{$p$ Value } \\
\hline & & B & Std. Error & & & \\
\hline \multirow{6}{*}{ Model 1} & Variables & & & & & \\
\hline & IE & 0.257 & 0.046 & 0.275 & 5.616 & 0.000 \\
\hline & $\mathrm{FE}$ & 0.385 & 0.058 & 0.334 & 6.588 & 0.000 \\
\hline & $\mathrm{EE}$ & -0.067 & 0.054 & -0.056 & -1.254 & 0.211 \\
\hline & $\mathrm{CE}$ & 0.106 & 0.046 & 0.115 & 2.295 & 0.022 \\
\hline & $\mathrm{BE}$ & 0.150 & 0.048 & 0.152 & 3.153 & 0.002 \\
\hline \multirow{10}{*}{ Model 2} & Variables & & & & & \\
\hline & IE & 0.384 & 0.178 & 0.412 & 2.155 & 0.032 \\
\hline & $\mathrm{FE}$ & 0.348 & 0.235 & 0.302 & 1.486 & 0.138 \\
\hline & $\mathrm{EE}$ & 0.161 & 0.210 & 0.133 & 0.765 & 0.445 \\
\hline & $\mathrm{CE}$ & -0.299 & 0.163 & -0.326 & -1.836 & 0.067 \\
\hline & $\mathrm{BE}$ & 0.320 & 0.396 & 0.325 & 0.810 & 0.419 \\
\hline & FEBE & 0.004 & 0.088 & 0.012 & 0.040 & 0.968 \\
\hline & EEBE & -0.102 & 0.084 & -0.471 & -1.218 & 0.224 \\
\hline & IEBE & -0.048 & 0.071 & -0.190 & -0.680 & 0.497 \\
\hline & CEBE & 0.160 & 0.063 & 0.686 & 2.545 & 0.011 \\
\hline
\end{tabular}

Dependent variable: UL, predictors: (constant), CE, EE, IE, FE, BE, predictors with interaction: (Constant), CE, EE, IE, FE, BE, IEBE, FEBE, EEBE, CEBE.

\section{Discussion}

The study was initiated to measure the effect of marketing engagement on users' loyalty who frequently use the social media in the presence of blogging in these sites. Measuring the loyalty level of its customers guides the companies for providing better and exceptional services. If these services are equipped with innovative ideas it may lead toward sustainable growth which ultimately contribute in the innovative ecosystem [30,67]. It was done through users' loyalty and marketing management where marketing engagement was further subdivided into innovative, functional, emotional, and communal engagement. Users' loyalty regarding social media usage was measured through the use of Facebook. To measure the relationship between marketing engagement and users' loyalty, two models and five hypotheses were proposed. These models and hypotheses were tested in SPSS using multiple regression technique. From calculated values of multiple regression, both model 1 and 2 were found to be statistically significant and explained the variation of 65 percent for simple regression, 66 percent in the presence of moderator and 67 percent in the presence of interaction terms. From above, it is confirmed that blogging only strengths and enhances the relationship of communal engagement with the users' loyalty for social media community. The results are also supported by previous studies $[34,68]$ 
where the communal engagement proved to influence the brand loyalty. For innovative, functional, and emotional engagements with their preferred electronic products, social media users still sought other channels apart from blogging [55]. The study has proposed a unique nomological network to measure the users' loyalty of social media community. Four types of users' engagements levels were measured in the presence of blogging as a moderator. However, blogging proved not to be a good moderator for innovative, functional, and emotional engagement by rejecting the hypotheses of $\mathrm{H} 2$, $\mathrm{H} 3$, and H4. The importance of blogging may be tested with different respondents e.g., non-electronic products can be measured for its authenticity in future research. Hypothesis 5 relating to communal engagement has been verified. This is because social media has emerged as a digital community platform that can be significantly influenced in the presence of blogging as a moderator. So, it is concluded that blogging partially acts as a moderator in the proposed model of this study by not considering the innovative, functional, and emotional engagement. However, based on the results in model 1 and significance level of communal engagement for $\mathrm{H} 5$, it is recommended that firms who want to boost their economic activities must not ignore the marketing engagement campaigns while considering the social media users' loyalty.

\subsection{Theoretical Contribution}

The study uniquely addressed the moderating role of blogging for social media users with the function of marketing engagement. So far, very few studies have targeted the social media users to measure their engagement and loyalty. Most of the firms still track the activities of its customers in a conventional or in offline modes. Such track records limit the ability of marketing firms to timely respond to the changing behaviors of its customers. In offline modes, the firms used the word of mouth (wom) technique as a tool of communication to influence its customers. Blogging is the advanced and updated form of wom where users can visualize and feel the products virtually while staying at home. Through bloggers opinion readily available on social media platforms (which can be deliberately hired by the firms) users can read the comments and directly interact with bloggers to enhance their familiarity and self-confidence with the buying product. Apart from gaining the trust of its customers, it is very easy to track and maintain the records of online customers and their interactions with the bloggers. Such instant and valuable information helped the marketing firms to offer personalized engagement marketing offers to earn the customer life-time value.

\subsection{Practical Implications}

Rapid evolvement of social media forced marketers to seek new methods of marketing research and business practices. Marketing engagement is one of the new techniques through which marketing firms persuade, motivate, and involve its customers to win their loyalty. Practically, it can be done by the deliberate efforts of the firm through blogging. From online expert's opinions, the users' not only gain the in-depth knowledge and details of that product but also gain confidence for purchasing and utilizing it. Such confidence and further experience enhanced the users' loyalty which ultimately is in the best interest of the marketing firms.

\subsection{Limitations}

The study was conducted by utilizing the primary data of social media users for online purchase of electronic products in a limited geographical area of Pakistan. From theoretical point of view, the study explained the 65 and 67 percent of variation through the proposed model before and after the inclusion of moderator. It showed that at least 33 percent unexplained variance can be explained with the inclusion of more predictors in the proposed model of this study. From practical point of view, a comprehensive database is missing to measure the effect of firms to engage its customers on social media. So, the non-probability sampling and referral groups were the only option to approach the respondents of this study. The use of such sampling technique may cause sampling bias by having 
lack of generalizability. These limitations can be overcome and the scope of study will be enhanced in future with regard to the availability of data and access to respondents.

\subsection{Future Recommendations}

The same framework can be used to measure the level of engagement and extent of loyalty of social media users for non-electronic products. Second, a larger pool of respondents from diverse geographical areas with larger sample size can be included for testing this model. The inclusion of diversified social media groups for electronic and non-electronic products will enhance the spatial and contextual prospects of the proposed framework of this study.

Author Contributions: Conceptualization, M.S. and U.Z.; methodology, M.S. and U.Z.; software, M.S.; validation, M.S.; formal analysis, M.S.; investigation, M.S.; resources, U.Z.; data curation, M.S. and U.Z.; writing-original draft preparation, M.S. and U.Z.; writing—review and editing, M.S. and U.Z.; project administration, M.S. and U.Z. All authors have read and agreed to the published version of the manuscript.

Funding: The authors received no financial support or external funding for the research, authorship, and publication of this article.

Conflicts of Interest: The authors declared no potential conflicts of interest with respect to the research, authorship, and publication of this article.

\section{References}

1. De Oliveira, R.T.; Indulska, M.; Steen, J.; Verreynne, M.-L. Towards a framework for innovation in retailing through social media. J. Retail. Consum. Serv. 2020, 54. [CrossRef]

2. Bhroin, N.N.; Milan, S. Media innovation and social change: Introduction to the special issue. J. Media Innov. 2020, 6, 1-8. [CrossRef]

3. Shanahan, T.; Tran, T.P.; Taylor, E.C. Getting to know you: Social media personalization as a means of enhancing brand loyalty and perceived quality. J. Retail. Consum. Serv. 2019, 47, 57-65. [CrossRef]

4. Schmitt, P.; Skiera, B.; Van den Bulte, C. Referral programs and customer value. J. Mark. 2011, 75, 46-59. [CrossRef]

5. Kim, H.; Park, S.-Y.; Joh, W.-I. A study on technology development performance and technology commercialization performance according to the technology development capability of smes focusing on a comparative analysis of technology business groups. J. Open Innov. Technol. Mark. Complex. 2019, 5, 65. [CrossRef]

6. Harmeling, C.M.; Moffett, J.W.; Arnold, M.J.; Carlson, B.D. Toward a theory of customer engagement marketing. J. Acad. Mark. Sci. 2017, 45, 312-335. [CrossRef]

7. Plaisime, M.; Robertson-James, C.; Mejia, L.; Núñez, A.; Wolf, J.; Reels, S. Social media and teens: A needs assessment exploring the potential role of social media in promoting health. Soc. Media Soc. 2020. [CrossRef]

8. Laroche, M.; Habibi, M.R.; Richard, M.-O. To be or not to be in social media: How brand loyalty is affected by social media? Int. J. Inf. Manag. 2013, 33, 76-82. [CrossRef]

9. Ashley, C.; Tuten, T. Creative strategies in social media marketing: An exploratory study of branded social content and consumer engagement. Psychol. Mark. 2015, 32, 15-27. [CrossRef]

10. Hadcroft, P.; Jarratt, D. Market orientation: An iterative process of customer and market engagement. J. Bus. Bus. Mark. 2007, 14, 21-57. [CrossRef]

11. Prasanna, R.; Jayasundara, J.; Naradda Gamage, S.K.; Ekanayake, E.; Rajapakshe, P.; Abeyrathne, G. Sustainability of smes in the competition: A systemic review on technological challenges and sme performance. J. Open Innov. Technol. Mark. Complex. 2019, 5, 100. [CrossRef]

12. Ellison, G.; Fudenberg, D. Word-of-mouth communication and social learning. Q. J. Econ. 1995, 110, 93-125. [CrossRef]

13. Baber, A.; Thurasamy, R.; Malik, M.I.; Sadiq, B.; Islam, S.; Sajjad, M. Online word-of-mouth antecedents, attitude and intention-to-purchase electronic products in pakistan. Telemat. Inform. 2016, 33, 388-400. [CrossRef] 
14. Loxton, M.; Truskett, R.; Scarf, B.; Sindone, L.; Baldry, G.; Zhao, Y. Consumer behaviour during crises: Preliminary research on how coronavirus has manifested consumer panic buying, herd mentality, changing discretionary spending and the role of the media in influencing behaviour. J. Risk Financ. Manag. 2020, 13, 166. [CrossRef]

15. Tiago, M.T.P.M.B.; Veríssimo, J.M.C. Digital marketing and social media: Why bother? Bus. Horiz. 2014, 57, 703-708. [CrossRef]

16. Ling, K.; Beenen, G.; Ludford, P.; Wang, X.; Chang, K.; Li, X.; Cosley, D.; Frankowski, D.; Terveen, L.; Rashid, A.M. Using social psychology to motivate contributions to online communities. J. Comput. Mediat. Commun. 2005, 10. [CrossRef]

17. Hampton, K.N.; Lee, C.-j.; Her, E.J. How new media affords network diversity: Direct and mediated access to social capital through participation in local social settings. New Media Soc. 2011, 13, 1031-1049. [CrossRef]

18. Sood, S.C.; Pattinson, H.M. 21st century applicability of the interaction model: Does pervasiveness of social media in b2b marketing increase business dependency on the interaction model? J. Cust. Behav. 2012, 11, 117-128. [CrossRef]

19. Rasiah, R. Building networks to harness innovation synergies: Towards an open systems approach to sustainable development. J. Open Innov. Technol. Mark. Complex. 2019, 5, 70. [CrossRef]

20. Reed, R.; Storrud-Barnes, S.; Jessup, L. How open innovation affects the drivers of competitive advantage: Trading the benefits of ip creation and ownership for free invention. Manag. Decis. 2012, 50, 58-73. [CrossRef]

21. Choi, J.-I.; Markham, S. Creating a corporate entrepreneurial ecosystem: The case of entrepreneurship education in the rtp, USA. J. Open Innov. Technol. Mark. Complex. 2019, 5, 62. [CrossRef]

22. Yun, J.J.; Zhao, X.; Jung, K.; Yigitcanlar, T. The culture for open innovation dynamics. Sustainability 2020, $12,5076$. [CrossRef]

23. Parveen, S.; Senin, A.A.; Umar, A. Organization culture and open innovation: A quadruple helix open innovation model approach. Int. J. Econ. Financ. Issues 2015, 5, 335-342.

24. Dabija, D.-C.; Bejan, B.M.; Pușcaș, C. A qualitative approach to the sustainable orientation of generation $\mathrm{z}$ in retail: The case of romania. J. Risk Financ. Manag. 2020, 13, 152. [CrossRef]

25. Nisar, T.M.; Whitehead, C. Brand interactions and social media: Enhancing user loyalty through social networking sites. Comput. Hum. Behav. 2016, 62, 743-753. [CrossRef]

26. Hawkins, K.; Vel, P. Attitudinal loyalty, behavioural loyalty and social media: An introspection. Mark. Rev. 2013, 13, 125-141. [CrossRef]

27. Potgieter, L.M.; Naidoo, R. Factors explaining user loyalty in a social media-based brand community. S. Afr. J. Inf. Manag. 2017, 19, 1-9. [CrossRef]

28. Ningthoujam, S.; Manna, R.; Gautam, V.; Chauhan, S. Building customer engagement and brand loyalty through online social media: An exploratory study. Int. J. Electron. Mark. Retail. 2020,11, 143-160. [CrossRef]

29. Nguyen, B.; Yu, X.; Melewar, T.; Chen, J. Brand innovation and social media: Knowledge acquisition from social media, market orientation, and the moderating role of social media strategic capability. Ind. Mark. Manag. 2015, 51, 11-25. [CrossRef]

30. Durana, P.; Valaskova, K.; Vagner, L.; Zadnanova, S.; Podhorska, I.; Siekelova, A. Disclosure of strategic managers' factotum: Behavioral incentives of innovative business. Int. J. Financ. Stud. 2020, 8, 17. [CrossRef]

31. Sawhney, M.; Verona, G.; Prandelli, E. Collaborating to create: The internet as a platform for customer engagement in product innovation. J. Interact. Mark. 2005, 19, 4-17. [CrossRef]

32. Criscuolo, C.; Haskel, J.E.; Slaughter, M.J. Global engagement and the innovation activities of firms. Int. J. Ind. Organ. 2010, 28, 191-202. [CrossRef]

33. Foroudi, P.; Jin, Z.; Gupta, S.; Melewar, T.; Foroudi, M.M. Influence of innovation capability and customer experience on reputation and loyalty. J. Bus. Res. 2016, 69, 4882-4889. [CrossRef]

34. Lim, J.S.; Hwang, Y.; Kim, S.; Biocca, F.A. How social media engagement leads to sports channel loyalty: Mediating roles of social presence and channel commitment. Comput. Hum. Behav. 2015, 46, 158-167. [CrossRef]

35. Brooks, A.; Todd, A.W.; Tofflemoyer, S.; Horner, R.H. Use of functional assessment and a self-management system to increase academic engagement and work completion. J. Posit. Behav. Interv. 2003, 5, 144-152. [CrossRef]

36. Kim, J.; Spielmann, N.; McMillan, S.J. Experience effects on interactivity: Functions, processes, and perceptions. J. Bus. Res. 2012, 65, 1543-1550. [CrossRef] 
37. Tomar, D.M.; Pandey, D.K.K.; Punia, D.D.K. Customer engagement on social media: Understanding the functional perspectives of social media towards customer engagement. Int. J. Mark. Hum. Resour. Manag. 2016, 7, 60-63.

38. Labrecque, L.I. Fostering consumer-brand relationships in social media environments: The role of parasocial interaction. J. Interact. Mark. 2014, 28, 134-148. [CrossRef]

39. Gerbaudo, P.; Marogna, F.; Alzetta, C. When "positive posting" attracts voters: User engagement and emotions in the 2017 uk election campaign on facebook. Soc. Media Soc. 2019. [CrossRef]

40. Molinillo, S.; Aguilar-Illescas, R.; Anaya-Sánchez, R.; Vallespín-Arán, M. Exploring the impacts of interactions, social presence and emotional engagement on active collaborative learning in a social web-based environment. Comput. Educ. 2018, 123, 41-52. [CrossRef]

41. Siefert, C.J.; Kothuri, R.; Jacobs, D.B.; Levine, B.; Plummer, J.; Marci, C.D. Winning the super "buzz" bowl: How biometrically-based emotional engagement correlates with online views and comments for super bowl advertisements. J. Advert. Res. 2009, 49, 293-303. [CrossRef]

42. Mollen, A.; Wilson, H. Engagement, telepresence and interactivity in online consumer experience: Reconciling scholastic and managerial perspectives. J. Bus. Res. 2010, 63, 919-925. [CrossRef]

43. Hull, K.; Lewis, N.P. Why twitter displaces broadcast sports media: A model. Int. J. Sport Commun. 2014, 7, 16-33. [CrossRef]

44. Shen, Y.-C.; Huang, C.-Y.; Chu, C.-H.; Liao, H.-C. Virtual community loyalty: An interpersonal-interaction perspective. Int. J. Electron. Commer. 2010, 15, 49-74. [CrossRef]

45. Chi, H.-H. Interactive digital advertising vs. Virtual brand community: Exploratory study of user motivation and social media marketing responses in Taiwan. J. Interact. Advert. 2011, 12, 44-61. [CrossRef]

46. Li, T.; Berens, G.; de Maertelaere, M. Corporate twitter channels: The impact of engagement and informedness on corporate reputation. Int. J. Electron. Commer. 2013, 18, 97-126. [CrossRef]

47. Schmidt, J. Blogging practices: An analytical framework. J. Comput. Mediat. Commun. 2007, 12, 1409-1427. [CrossRef]

48. Thevenot, G. Blogging as a social media. Tour. Hosp. Res. 2007, 7, 287-289. [CrossRef]

49. Hynnä, K.; Kyrölä, K. "Feel in your body": Fat activist affects in blogs. Soc. Media Soc. 2019. [CrossRef]

50. Graham, M. Geography/internet: Ethereal alternate dimensions of cyberspace or grounded augmented realities? Geogr. J. 2013, 179, 177-182. [CrossRef]

51. Andrews, P. Is blogging journalism? Nieman Rep. 2003, 57, 63.

52. Flanagin, A.J.; Metzger, M.J.; Pure, R.; Markov, A.; Hartsell, E. Mitigating risk in ecommerce transactions: Perceptions of information credibility and the role of user-generated ratings in product quality and purchase intention. Electron. Commer. Res. 2014, 14,1-23. [CrossRef]

53. Jansen, B.J.; Sobel, K.; Cook, G. Classifying ecommerce information sharing behaviour by youths on social networking sites. J. Inf. Sci. 2011, 37, 120-136. [CrossRef]

54. Hsu, C.-P.; Huang, H.-C.; Ko, C.-H.; Wang, S.-J. Basing bloggers' power on readers' satisfaction and loyalty. Online Inf. Rev. 2014, 38, 78-94. [CrossRef]

55. Yoo, C.W.; Sanders, G.L.; Moon, J. Exploring the effect of e-wom participation on e-loyalty in e-commerce. Decis. Support Syst. 2013, 55, 669-678. [CrossRef]

56. Sadiq, W.; Abdullah, I.; Aslam, K.; Zulfiqar, S. Engagement marketing: The innovative perspective to enhance the viewer's loyalty in social media and blogging e-commerce websites. Mark. Manag. Innov. 2020, 20, 149-166. [CrossRef]

57. Schillewaert, N.; Langerak, F.; Duharnel, T. Non-probability sampling for www surveys: A comparison of methods. Int. J. Mark. Res. 1998, 40,1-13. [CrossRef]

58. Nechaev, A.S.; Antipin, D.A.; Antipina, O.V. Efficiency estimation of innovative activity the enterprises. J. Math. Stat. 2014, 10, 443-447. [CrossRef]

59. Child, J.T.; Pearson, J.C.; Petronio, S. Blogging, communication, and privacy management: Development of the blogging privacy management measure. J. Am. Soc. Inf. Sci. Technol. 2009, 60, 2079-2094. [CrossRef]

60. Cronbach, L.J. Coefficient alpha and the internal structure of tests. Psychometrika 1951, 16, 297-334. [CrossRef]

61. Santos, J.R.A. Cronbach's alpha: A tool for assessing the reliability of scales. J. Exterm. 1999, 37, 1-5.

62. Peterson, R.A.; Kim, Y. On the relationship between coefficient alpha and composite reliability. J. Appl. Psychol. 2013, 98, 194-198. [CrossRef] [PubMed]

63. Zaiţ, A.; Bertea, P. Methods for testing discriminant validity. Manag. Mark. J. 2011, 9, 217-224. 
64. Farrell, A.M. Insufficient discriminant validity: A comment on bove, pervan, beatty, and shiu (2009). J. Bus. Res. 2010, 63, 324-327. [CrossRef]

65. Menard, S. Six approaches to calculating standardized logistic regression coefficients. Am. Stat. 2004, 58, 218-223. [CrossRef]

66. Yuan, K.-H.; Chan, W. Biases and standard errors of standardized regression coefficients. Psychometrika 2011, 76, 670-690. [CrossRef]

67. Lee, J.; Park, J.S.; Lee, J. The impact of multimarket competition on innovation strategy: Evidence from the korean mobile game industry. J. Open Innov. Technol. Mark. Complex. 2020, 6, 14. [CrossRef]

68. Brodie, R.J.; Ilic, A.; Juric, B.; Hollebeek, L. Consumer engagement in a virtual brand community: An exploratory analysis. J. Bus. Res. 2013, 66, 105-114. [CrossRef]

(C) 2020 by the authors. Licensee MDPI, Basel, Switzerland. This article is an open access article distributed under the terms and conditions of the Creative Commons Attribution (CC BY) license (http://creativecommons.org/licenses/by/4.0/). 